\title{
OS NETOS QUE SALAZAR NÃO TEVE: GUERRA COLONIAL E MEMÓRIA DE SEGUNDA GERAÇÃO
}

\author{
Margarida Calafate Ribeiro \\ António Sousa Ribeiro \\ (Centro de Estudos Sociais, Universidade de Coimbra)
}

\section{RESUMO}

Como tem vindo a ser recorrentemente argumentado, a guerra, enquanto fenómeno bélico, social e político, atinge sempre pelo menos três gerações: a geração que é para ela chamada, a geração dos pais dos mobilizados e a geração dos filhos da guerra. A partir dos dados obtidos projeto "Os Filhos da Guerra Colonial: pós-memória e representações", financiado pela Fundação para a Ciência e Tecnologia e realizado no Centro de Estudos Sociais da Universidade de Coimbra, entre 2007-2011, e em que os autores participaram, este artigo analisa a memória de segunda geração da Guerra Colonial portuguesa, através dos testemunhos recolhidos e da análise das representações artísticas e literárias a que este tipo de memória, ou melhor, pós-memória, tem vindo a dar origem.

PALAVRAS CHAVE: Guerra Colonial, memória de segunda geração, testemunho, representação.

\begin{abstract}
As has been repeatedly argued, war, as a social and political phenomenon, strikes at least three generations: the generation that is call, the parent's generation and the generation of the children of the war. From the data obtained from the project "Children of the Colonial Wars: post-memory and representations", funded by the Foundation for Science and Technology and carried out at the Centre for Social Studies, University of Coimbra, between 2007-2011, this paper analyses the memory of the second generation of the Portuguese Colonial War, through both testimonies of children of the Colonial Wars and their literary and artistic representations of the Colonial Wars.
\end{abstract}

KEYWORDS: Colonial Wars, second generation memory, testimony, representation. 
"Nenhum Juízo Final, meus filhos, pode dar-lhes

aquele instante que não viveram, aquele objeto

que não fruíram, aquele gesto

de amor, que fariam 'amanhã'.

E, por isso, o mesmo mundo que criemos

nos cumpre tê-lo com cuidado, como coisa

que não é nossa, que nos é cedida

para a guardarmos respeitosamente

em memória do sangue que nos corre nas veias,

da nossa carne que foi outra, do amor que

outros não amaram porque lho roubaram."

Jorge de Sena, "Carta aos meus filhos sobre os fuzilamentos de Goya"

Como tem vindo a ser recorrentemente argumentado, a guerra, enquanto fenómeno bélico, social e político, atinge sempre pelo menos três gerações: a geração que é para ela chamada, a geração dos pais dos mobilizados e a geração dos filhos da guerra. A geração da guerra é composta pelos homens mobilizados e pelas mulheres, noivas, namoradas ou irmãs; a geração dos pais destes jovens mobilizados é frequentemente representada pela mãe, classicamente ligada à imagem da mater dolorosa, que vê na guerra a destruição da sua função de maternidade. Por isso, o discurso clássico militarista de apelo à guerra e à mobilização contempla sempre as mulheres, mães e esposas, procurando envolvê-las num consenso social tendente à aceitação do sacrifício alegadamente partilhado por todos e por todas, em nome de valores como a defesa da pátria ou da liberdade, mas também da proteção das mulheres e crianças perante inimigos implacáveis. No pós-guerra, é também sobre as mulheres que recai a esperança do retorno a uma certa normalidade, que possibilite a reintegração dos regressados das frentes de combate nas famílias e, por extensão, na sociedade.

Relativamente à Guerra Colonial portuguesa, que decorreu entre 1961-74 nas então colónias africanas portuguesas de Angola, Moçambique e Guiné- Bissau, o apelo feito foi em defesa da "nação una e indivisível", como ocorrera aliás nas guerras da Indochina e da Argélia, protagonizadas pela França. São guerras todas estas que ocorrem num tempo, o final dos anos 50 e os anos 60, em que, como era bem visível já na altura, os processos de libertação e o fim dos impérios coloniais europeus eram irreversíveis. Assim, não só estas guerras nunca poderiam terminar em vitória do ponto de vista militar - porque não se vence militarmente uma guerra de guerrilha -, mas também, por moralmente inaceitáveis, estavam destinadas a um percurso de crescente deslegitimação. A história que delas pudesse vir a ser contada nunca poderia aspirar à "vitória narrativa" conseguida, mesmo que precariamente, pela Guerra do Vietname sobretudo a partir de algumas representações cinematográficas. $\mathrm{O}$ facto é que a Guerra do Vietname, protagonizada pelas forças armadas norte-americanas, buscava 
legitimar-se através de um discurso de salvação do mundo frente ao "perigo comunista", na lógica geopolítica da Guerra Fria, e não em nome da manutenção de uma secular dominação colonial, visivelmente condenada pelos processos de libertação em curso na África e na Ásia a partir dos primeiros anos do pós-guerra.

Todo este contexto global era, por via de regra, opaco para as mães portuguesas, habitantes de um meio pequeno, desinformado, católico, conservador e resignado, que aceitaram o apelo como se aceitava a pobreza, a falta de educação formal, a falta de informação. Daí que, no que diz respeito à Guerra Colonial, fique tão penosamente visível a dimensão sempre pessoal e privada do sofrimento e do lamento, liminarmente abafados nos poucos momentos em que atingiam expressão pública (recorde-se as revoltas logo silenciadas no cais de Alcântara ${ }^{1}$ ). A revolta exprimir-se-ia depois da mesma forma silenciosa através do envio dos filhos, sobretudo os mais novos, para o estrangeiro, não tanto como ato de deserção, que implicava um envolvimento político que a maioria dos portugueses não tinha, mas nos caminhos da emigração tradicionalmente contabilizada como económica.

Para estas duas gerações, a dos pais e a dos filhos mobilizados e suas mulheres, a Guerra Colonial foi essencialmente um percurso de perdas: perda dos filhos, perda da juventude, da família, da inocência, da vida, resumida na perda do mundo anterior à guerra para aqueles que eram forçados a combater, mesmo que não manifestando qualquer apoio ideológico à guerra; ${ }^{2}$ perda do país, da vida, da família, da normalidade para os que optaram politicamente pela deserção, pelo exílio ou pela emigração; e, para aqueles que lutavam convictamente por um Portugal imperial, perda da nação, perda dos filhos, que nunca voltariam como os heróis idealizados, mas também, em muitos casos, perda da inocência política e do seguidismo inquestionado de Salazar. Esta geração dos pais da Guerra Colonial, educada ainda, tal como o seu líder, nos ideais da nação imperial saída do Ultimatum inglês, vai, a prazo, começar a questionar o elevado preço a pagar pela manutenção de tal império. O questionamento sobre as razões objetivas da partida do filho é a primeira intromissão do espaço privado no público, resultando na primeira configuração intergeracional produzida por esta guerra. Essa é a história privada vivida pelo poeta Fernando Assis Pacheco e pelo seu pai, num diálogo que transborda da escrita íntima das cartas para a poesia. Como muitos outros pais que tiveram os filhos envolvidos na Guerra Colonial, o pai do poeta, destinatário de uma correspondência que lhe trazia um filho esfacelado e uma verdade diferente sobre os valores em que acreditava, foi vendo os seus mitos, traçados no pequeno espaço político e moral do salazarismo, esboroarem-se à luz da experiência vivida pelo filho. Desta forma, cumpria-se a funcionalidade e a eficácia do testemunho prestado pelo filho, começando a abrir-se uma fissura, ainda que muitas vezes ambígua e hesitante, nos valores ideológicos e morais das famílias que anonimamente apoiavam o regime, mas começavam a interrogar-se sobre o elevado preço que lhes era exigido (RIBEIRO, 2004, p. 207-211) 
E assim o "velho abutre", como lhe chamou Sophia de Mello Breyner Andresen, foi começando a perder a sua base social de apoio e o seu percurso foi divergindo do povo que dizia representar, um povo alicerçado exatamente a partir da pequena célula social da família, que o ditador tanto defendia, mas que na verdade nunca constituiu, e que agora desmembrava em nome da defesa da pátria, enviando a juventude para a guerra e levando outros tantos aos caminhos da emigração em fuga da pobreza, da falta de desenvolvimento, da guerra. No momento de colaborar na defesa da nação, aquele que nos anos 30 se tinha apresentado ao povo português como "católico, pobre filho de pobres" e assim se identificava com toda a população e se auto-elegia como representante orgânico do país inteiro, não podia agora, nos anos 60, apresentar-se como "pai, com um filho no Ultramar", como então se dizia.

\section{E COMO CONTAR ESSA VIVÊNCIA, COMO ASSUMIR ESSA HERANÇA?}

Como hoje nos é bem possível ver, a Guerra Colonial era, desde o momento em que começou, um percurso para a derrota, pois constituia de facto o início - violento, conturbado, mas, sem dúvida, o início - do processo de descolonização. Também o seu final estaria marcado por muitos equívocos: no mesmo momento em que termina, quer-se logo vivê-la e lê-la como história, ou pura e simplesmente deixá-la em África como se fosse possível fazê-la desacontecer. Na euforia dos novos tempos, o 25 de Abril rapidamente se tornou um exemplo de revolução pacífica, esquecendo-se assim todo o sangue de África, tanto mais que a imagem das forças armadas empenhadas na Guerra Colonial se transfigura da noite para o dia na imagem salvífica de um MFA libertador; o "Ultramar" passava à história, apesar de estoirar todos os dias na nova casa política portuguesa, fosse sob a forma dos retornados, do regresso de ex-combatentes, das notícias dos países africanos em que o processo de transição era intensamente vivido dia a dia. Desta forma, no pós-25 de Abril, a Guerra Colonial torna-se rapidamente um silêncio, algo que não era recomendável recordar publicamente, invisível e, portanto, reservada aos grupos directamente portadores da sua memória: os ex-combatentes e as suas famílias. Que testemunho poderia então ser dado sobre a Guerra Colonial? Que condições de receção havia na sociedade portuguesa para a audição deste testemunho? Quem estava de facto interessado em ouvir falar sobre o que se tinha passado em África?

Para que haja testemunho, é necessário que exista um interesse por parte da sociedade em conhecer aquilo que é testemunhado, um interesse que, por exemplo, no imediato pós-Segunda Guerra Mundial, não existia na sociedade alemã (e na sociedade europeia em geral) relativamente à experiência dos campos de extermínio nazis; como não havia na sociedade portuguesa pós-25 de Abril interesse em saber o que se tinha passado em África, nem com a guerra, nem com os colonos. Pela sua natureza, pelo 
momento político de libertação trazido pelo 25 de Abril, a Guerra Colonial resiste logo de início a ser nomeada - Guerra do Ultramar, Guerra de África, Guerra Colonial - e resiste à narrativa, tornando-se inconfessada e inconfessável. Na verdade, e ao contrário da guerra do Vietname que, apesar de uma grande derrota do Ocidente, representa a primeira guerra pós-colonial que, de certa maneira, vence pela narrativa graças particularmente ao poder das ficções cinematográficas - as guerras coloniais partem de um paradigma narrativo derrotado antes de acontecer, porque as próprias condições do seu pronunciamento estão a priori derrotadas. Como enquadrar uma narrativa que, na verdade, vai pugnar por uma ordem anacrónica e historicamente injusta? Mas também como silenciar uma experiência que foi a mais marcante nas vidas de tantos portugueses? Como torná-la audível a não ser pelo ressentimento e pelo relato de perdas? Daí portanto e também a dificuldade do testemunho, e da passagem do testemunho, pela impossibilidade de contar uma história que, aparentemente, surge de antemão confinada ao foro privado e incapaz de obter ressonância na esfera da memória pública.

É neste mar de silêncios que a Guerra atinge a geração dos filhos, a geração que era criança ou ainda nem era nascida aquando da mobilização do pai, a geração dos "filhos da guerra", ou dos netos que Salazar não teve. É a estes filhos que a geração dos pais apela hoje plena de dúvidas e ansiedades. Ouça-se, por exemplo, António Lobo Antunes: "Não posso esquecer. Não consigo esquecer. Eu o 07890263 ORH+ não consigo esquecer. [...] Eu estive lá. Eu vi. [...] Se eu saltar com o rebenta-minas que fique, ao menos, o eco do meu grito. Completem esta crónica, vocês, os que cá ficam. 07890263 ORH+. Filha." (ANTUNES, 2002). Ou José do Carmo Francisco:

"Rossio/ Odivelas"

As botas pesavam mais na Alameda das Linhas de Torres, à porta do quartel, em mil novecentos e setenta e dois.

Hoje não há patrulhas, come-se bem, a guerra só nos filmes.

Alguns dos nossos filhos não acreditam... (FRANCISCO, 1987, p. 10)

Ou ainda uma mulher entrevistada para África no Feminino:

Quando me vim embora, perguntava a mim mesma: "Daqui a vinte anos, quando os meus filhos me perguntarem 'o que é que estiveste lá a fazer?', meu Deus, o que é que lhes vou dizer? Como é que lhes vou explicar?" Não era nada agradável, e ainda hoje não é. Quando se tem culpa numa situação, não há desculpabilização possível, tem de se viver com ela. Por muito que se explique, explicar não é justificar. (RIBEIRO, 2007, p. 55)

As questões lançadas nos textos apresentados conduzem-nos a 
vários problemas relacionados com a possibilidade de elaboração do testemunho, a possibilidade de passar o testemunho e, no limite, as próprias condições de emissão e receção desse testemunho. Ou seja: seriam os pais capazes de contar a história da guerra? E que história? Estariam os filhos e, num sentido mais alargado, a sociedade portuguesa disponíveis e interessados em ouvir o testemunho?

Estas interrogações levam-nos não apenas às condições de pronunciamento do testemunho, mas ao próprio processo de testemunhar, em que não apenas o conteúdo imediato da história narrada, mas também o gesto e a voz de quem testemunha não são separáveis da figura de quem cria as condições para que seja possível o ato de enunciação. É, pois, necessário pela parte de quem ouve criar um contexto em que a articulação do testemunho se torne possível e sintonizar-se com a dimensão performativa de uma situação de enunciação em que os silêncios, os gestos, a linguagem corporal, podem ser tão importantes como as palavras. A atenção a este carácter performativo do testemunho permite que ele seja entendido na sua complexidade, ou seja, não simplesmente como transmissão, mas como produção de memória, e, assim, como ato de inscrição do sujeito na história. Só assim se processa o mecanismo de reconhecimento e de compaixão necessários a quem fala, que assim se liberta do peso de uma memória antes condenada ao silêncio; quem ouve terá a partir de então de lidar com o testemunho recebido, inscrevendo na sua própria identidade o testemunho que acaba de ouvir. É assim que, no caso de segunda geração, se assumem as identidades de "filho do Holocausto", "filho de desaparecido", "filho de preso político", "filho da Guerra Colonial".

\section{E QUEM É ENTÃO ESTE "FILHO DA GUERRA"?}

$\mathrm{O}$ "filho da guerra" é alguém para quem a guerra é já apenas uma representação. Ele não tem a titularidade da experiência, nem é autor do testemunho, mas é o herdeiro simbólico de uma ferida aberta sobre a qual elabora uma narrativa - um testemunho possível, um testemunho mediado, um testemunho adotivo, na aceção de alguns teóricos - construído a partir de fragmentos das narrativas familiares, compostas por discursos, fotografias, mapas, cartas, aerogramas, baralhos de cartas, camuflados e outros objetos do domínio privado, que constituem uma espécie de "naturezas mortas" da Guerra Colonial, e também por fragmentos retirados de narrativas públicas. A pós-memória ${ }^{3}$ ou a memória de segunda geração surge, assim, como uma "herança" direta ou indireta de uma experiência traumática que, ainda que vivida por outro, teve reflexo na esfera privada ou familiar e, portanto, pode ser assumida como um legado explícito ou mediado e pode ser reelaborada a partir do "testemunho de um testemunho”. A pós-memória não coincide portanto com a memória pessoal, mas funciona, na sua condição de "não-experimentado", como uma memória do "quase" ou do "como se", como refere Rafaella di Castro falando da memória de terceira geração do Holocausto (DI CASTRO, 2008). 
É importante sublinhar que, no caso da Guerra Colonial, os fragmentos que sustentam a construção da pós-memória têm um enquadramento familiar, ou seja, estão conservados numa casa de família em que o filho da guerra cresceu, ao contrário de outros casos, como por exemplo, o do Holocausto ou, para adotar a expressão de Beatriz Sarlo, da memória de segunda geração, relativamente aos filhos de presos políticos das ditaduras sul-americanas. Nestes casos, com referência extrema ao Holocausto, a fragmentação familiar é profunda, tornando-se, assim, os poucos objetos eventualmente recuperados, como fotografias ou pertences dos antepassados - muitas vezes o próprio nome -, rastos essenciais para possibilitar a reconstrução das identidades. Esta situação explica de alguma forma a quase obsessão com a rememoração, perante a suspensão da vida a que a destruição do arquivo conduziu. No caso da pós-memória da Guerra Colonial, o arquivo - as fotografias, os aerogramas, os objetos - e os próprios protagonistas estão presentes na casa familiar, o que, muito frequentemente, permite reconstruir uma história sem passar pelo testemunho do pai, seja porque esse testemunho não foi pedido, seja porque, mesmo quando existe uma narrativa explícita por parte do progenitor, o silêncio sobre as dimensões mais traumáticas da experiência vivida por este se mantém como regra. Na verdade, muitos depoimentos de ex-combatentes coincidem na afirmação de que não tem havido ao longo dos anos condições favoráveis à articulação dos seus testemunhos, ouvidos muitas vezes pelos filhos com algum cansaço por serem mais ou menos sempre as mesmas histórias, raramente capazes de mergulhar nas dimensões mais complexas, mais próximas do indizível da violência e do trauma, e, portanto, longe de satisfazer a necessidade de compreender sentida pela segunda geração. Esta situação explica também o silêncio, o alheamento inexplicável do pai em vários momentos, as explicações da mãe face a alguma disfunção do pai - "o teu pai está assim porque andou na guerra” - e, sobretudo, o espanto e a distância dos filhos perante uma história que, mesmo que apenas entrevista, surge como quase inacreditável. Finalmente, tudo isto contribui também para explicar o prolongamento para a geração dos filhos da ausência de questionamento político sobre as razões que envolveram a geração dos pais no conflito. E essa é potencialmente a mais pesada herança, não só da guerra, mas, sobretudo, da ditadura. Quando Primo Levi fala do "dever de memória”, fala não apenas da necessidade da passagem do testemunho, mas também da discussão em volta das razões que levaram a que aquele testemunho, que o dever da memória impõe, fosse possível e articulável, isto é, de uma dimensão que está para além da esfera privada e se torna necessariamente política, em todos os sentidos da palavra (LEVI, 1997). ${ }^{4}$

No campo hoje em dia muito fértil dos estudos sobre trauma, memória e identidade, tem vindo a ser sublinhado o facto de a construção da memória não corresponder a processos de transmissão linear, mas antes decorrer de modo "multidireccional” (ROTHBERG, 2009), no seio de situações ambivalentes de tensão e de conflito em que cada sujeito procura lan- 
çar mão de referências que são necessariamente heterogéneas, mas que, do seu ponto de vista, podem sustentar um modo produtivo de relacionamento com um passado que surge como relevante para a afirmação da sua identidade. Esses processos não ocorrem simplesmente no plano individual, antes envolvem "comunidades de memória" (PICKERING; KEIGHTLEY, 2013), representadas antes de mais pelo universo familiar, mas que podem envolver muitas outras dimensões, desde logo, a dimensão geracional.

O que nos mostra a pós-memória da Guerra Colonial que estudámos no âmbito do projeto "Os Filhos da Guerra Colonial: pós-memória e representações” - é, justamente, que a Guerra Colonial em África, ainda que, da perspetiva dos filhos, muitas vezes incompreensível, distante e sem justificação plausível, está claramente presente no horizonte desta segunda geração através de mecanismos de reconhecimento estruturados, para usar um conceito desenvolvido por Emily Keightley e Michael Pickering (2012), a partir de uma “imaginação mnemónica" capaz de gerar narrativas identitárias estruturadas tanto no plano de uma memória privada de âmbito familiar, como no plano de uma memória pública, neste último caso, sobretudo pela via do trabalho artístico criado pelos filhos a partir da experiência dos pais.

Nas mais de 150 entrevistas que realizámos a filhos da guerra, destacámos três grupos, cujas identidades foram particularmente marcadas pela vivência ou opção do pai relativamente à Guerra Colonial. Um primeiro grupo composto pelos filhos de homens que voltaram da guerra com perturbações físicas ou psicológicas, estas nem sempre medicamente reconhecidas; um outro composto pelos filhos de homens que não fizeram a guerra porque optaram por desertar; e, finalmente, aqueles que - na esmagadora maioria dos casos, com base na relação familiar - a partir do puzzle de imagens e histórias que compõem uma história herdada da Guerra Colonial, enveredaram pelo ato criativo e, portanto, pela reconstrução e a projeção imaginativa em modos de experiência alheios.

O primeiro grupo assume a identidade de filho da guerra, como alguém que desde muito cedo, teve de lidar com uma situação de conflito, violência ou estranhamento em casa, de que só mais tarde e, normalmente, através da mãe, começou a entender as razões. Trata-se de alguém que vive, como diz uma nossa entrevistada, "numa guerra onde nunca esteve", pois a guerra esteve desde criança em sua casa. A herança deste passado traumático do pai e da mãe (que muitas vezes também revela grande sofrimento e até doença do foro psiquiátrico por exaustão emocional), prolonga-se, assim, para os filhos que crescem envoltos num clima que raramente entendem, e em que duas atitudes aparentemente opostas, mas, por via de regra, concomitantes, são visíveis: por um lado a fuga ao tema, ausente das conversas pelo medo do que a memória da guerra possa despoletar; por outro, a vontade intensa de compreender o que de facto foi a Guerra Colonial para que a herança que carregam tenha algum sentido. A conclusão é normalmente insatisfatória: a percepção do logro enorme em que o pai 
esteve envolvido, o que gera normalmente, a vitimização do pai e a revolta, ao mesmo tempo que agudiza o espanto e a interrogação sobre o silêncio reinante na esfera pública em torno da Guerra Colonial, quando a guerra esteve sempre tão presente na trajetória familiar.

Desde que eu me lembro de mim em casa, sempre me lembro, da guerra, naquela casa, esteve sempre, sempre, sempre presente. Sempre, sempre. E saía de casa e pensava: e os outros, onde estão, ninguém lá esteve? $\mathrm{O}$ pais dos outros não foram à guerra?

Por que é que foi todo este sofrimento? [...] Para quê? [...] Sempre que há algum documentário na televisão, eu tento não perder. Preciso de tentar perceber. Ainda há grandes problemas..., muitos problemas, que as pessoas que lá andaram tiveram, e isso não é trazido para a praça pública, penso eu. [...] Acho que ninguém imagina o que as famílias passam, ter uma pessoa dessas em casa. E ninguém imagina, ninguém fala?

O segundo grupo, o grupo de filhos de desertores é, claramente, o mais politizado, mais cosmopolita e, genericamente, sente orgulho na opção feita pelo pai, na medida em que também tem uma maior informação e capacidade de questionamento do tema. Lida razoavelmente bem com alguma animosidade na sociedade portuguesa relativamente à posição do pai e vê a Guerra Colonial como algo absolutamente incompreensível, fora do tempo. É neste grupo que mais particularmente se nota e se percebe que a memória da Guerra Colonial, a memória de uma política nacional que pressupunha a subjugação colonial de outros povos em nome de uma nação passada, outrora expansionista, quando interrogada a partir da segunda geração não resiste à explicação e à justificação e, nessa medida, ela pode também constituir uma interpelação às gerações futuras sobre a legitimidade da violência e da dominação.

Se calhar em casa ouvi falar mais da ditadura. Ouvi falar mais nisso... no Salazar, nas PIDES e isso tudo. Entretanto, por acréscimo, esperem aí, afinal há uma Guerra Colonial. Houve uma altura que fiquei admirado não sei com que idade, deve ter sido na pré-adolescência, não sei... Fiquei admirado... ah! Fiquei até chocado. Nós também somos, também estivemos a ocupar outros territórios, também fomos colonialistas. [...]

Finalmente, um terceiro grupo que, a partir de um gesto de autor, contratualiza no espaço público aquilo que seria um diálogo possível com uma memória alheia, mas profundamente marcada na vida familiar. Temos em mente representações que podem, por exemplo, ter a forma de poemas, como na obra de Norberto do Vale Cardoso, filho de um ex-combatente que trouxe a guerra para casa; de filmes como A Costa dos Murmúrios, de Margarida Cardoso (2004), que constrói uma representação - o seu filme - sobre outra representação, A Costa dos Murmúrios, de Lídia Jorge; de 
documentários como o Ir à Guerra, de Marta Pessoa (2010), ou Deus não Quis, de António Ferreira, (2007); de peças de teatro como Ignara\#Guerra Colonial: fazer o trabalho de casa (2008), do Teatro Mosca, cuja encenação e representação é feita por filhos da guerra. São ainda músicas que, desde os anos 80, com Rui Veloso, Xutos \& Pontapés, ou os Delfins e "Aquele Inverno" de 1988, escrita por Fernando Cunha, e cujo clip é composto por fragmentos de um dos primeiros filmes portugueses sobre a Guerra Colonial, Um Adeus Português de João Botelho. São os trabalhos artísticos de Miguel Palma e de Ana Vidigal com "VOID” (o seu quarto de menina forrado com as fotografias e aerogramas do pai) ou "Penélope", a colcha que dedicou à mãe composta pelas cartas com que esta se deitou durante dois anos, nas palavras da artista. Mas, até ao momento são sobretudo romances como Daqui a nada (1992), de Rodrigues Guedes de Carvalho, Impressão Digital ou a tipografia de uma existência indizível (2005), de Norberto Vale Cardoso, Guardador de Almas, de Rui Vieira (2005), As sete estradinhas de Catete (2007), de Paulo Bandeira Faria, ou, ainda, de José Rodrigues dos Santos, O Anjo Branco (2009).

Os autores destes trabalhos constroem ficções romanceadas, poéticas, artísticas ou cinematográficas passadas em África ou sobre o regresso de África, baseadas em tempos, personagens e espaços relativos ao tempo da Guerra Colonial. São cenários, experiências, amores e diálogos que não tiveram, mas que provavelmente ouviram, pois fizeram parte da geração dos seus pais. Trata-se aliás, por vezes, de livros dedicados aos pais ${ }^{6}$ procurando assim um diálogo entre a geração que fez a Guerra Colonial e aquela que lhe sucedeu.

Até ao momento, tanto as propostas ficcionais, poéticas e artísticas elaboradas pelos filhos da guerra, como muitas das entrevistas que realizámos revelam múltiplas questões que só uma segunda geração pode suscitar sem cair, como a geração dos pais, no abismo da culpa ou do silêncio traumático. Nestes discursos, começam a ser tecidas as razões de tantas existências assombradas pelos fantasmas de África, pelo abandono, pela incompreensão, mas começam também a aparecer as primeiras reflexões mais elaboradas e politizadas sobre o que de facto foi a Guerra Colonial e os seus prolongamentos hoje na sociedade portuguesa. Todavia, o rasto biográfico que os funda evita o confronto e tende antes para a reconciliação possível, para o reconhecimento e para a compaixão, gerada por um pacto de partilha emocional, que faz com que o filho encontre na narração algo de si próprio, aproximando quem lembra de quem é testemunha de uma lembrança, testemunha do testemunho, que gera o pacto intergeracional dentro da esfera familiar e, depois, na esfera pública através dos gestos de autor.

Com os filhos, com os pais, com os fragmentos dispersos de narrativas compostas dos estilhaços do que foi a tragédia maior da história recente de Portugal, vai-se construindo uma pós-memória da Guerra Colonial, que representa a ressignificação e concomitante projeção para o espaço público de memórias muitas vezes antes vividas apenas na esfera 
privada. Vamos, assim, assistindo à construção de uma memória cultural da Guerra Colonial que, longe de limitada à transmissão linear de um conhecimento sobre o passado, se constitui como uma rede discursiva multifacetada e multidirecional fortemente radicada numa dimensão de contemporaneidade. Deste modo, para além dos protagonistas diretos e dos seus descendentes, a construção transgeracional de uma memória pública abre espaços para repensar a Guerra Colonial a partir da ressignificação das perdas e vácuos do passado, criando uma possibilidade outra de uma ética de representação da guerra e permitindo a definição coletiva de uma responsabilidade sobre o passado capaz de oferecer, se não a garantia, pelo menos a possibilidade de consolidação de uma democracia com memória.

\section{REFERÊNCIAS BIBLIOGRÁFICAS}

ACTON, Carol. Grief in Wartime: Private Pain, Public Discourse. New York: Palgrave Macmillan, 2007.

ANTUNES, António Lobo. 07890263 ORH+. In: Terceiro Livro de Crónicas. Lisboa: Dom Quixote, 2002, p. 111-114.

CASTRO, Raffaella Di. Testimoni del non-provato. Ricordare, pensare, immaginare la Shoah nella terza generazione. Roma: Carocci, 2008.

FRANCISCO, José do Carmo. Transporte Sentimental. Lisboa: Espiral, 52, 1987.

HIRSCH, Marianne. The Generation of Postmemory. Poetics Today, 29(1), 103-28, 2008.

HORTA, Maria Teresa. Poesia Completa 2 - 1967-1982. Lisboa: Litexa, 1983

KEIGHTLEY, Emily; PICKERING, Michael. The Mnemonic Imagination: Remembering as Creative Practice. Basingstoke: Palgrave Macmillan, 2012.

. Communities of Memory and the Problem of Transmission. European Journal of Cultural Studies, 16(1), 115-31.

LEVI, Primo. O dever de memória. Trad. Esther Mucznik. Porto: Civilização, 1997.

POSNER, Gerald L.. Os Filhos de Hitler - filhos de dirigentes do Terceiro Reich falam dos seus pais e de si próprios. Trad. Artur Lopes Cardoso. Lisboa: Editorial Notícias, 1996.

RAMOS, Rui et al. História de Portugal. Lisboa: A Esfera dos Livros, 2009.

RIBEIRO, Margarida Calafate. "Ainda falta um grito". Histórias de guerra, trauma e poesia na obra de Fernando Assis Pacheco. Rivista di Studi Portoghesi e Brasiliani. (3), p.65-85, 2001. 


\section{Recebido para publicação em 08/04/2013}

Aprovado em 16/07/2013

\section{NOTAS}

1 Desse lamento privado, pronunciado a medo, falam-nos poeticamente Maria Teresa Horta em "Lamento de uma Mãe, para um Filho soldado nas colónias" e Natércia Freire, relativamente à partida dos jovens para a Guerra Colonial no anos 60. "Meu filho posto/ soldado/ levado para lá do mar/ de negro ando vestida/ chorando-te até chegares/ Dois braços sei tu levavas/ com quantos voltas não sei.../ com duas pernas andavas/ e com os olhos enxergavas/ aqueles montes além/ Meu filho neste baraço/ de ódio que nunca vem.../ uma farda te vestiram e uma arma te entregaram/ a mando não sei de quem.../ Puz cinza nos meus cabelos/ e com um lenço os tapei/ vou chorar-te dia e noite/ nessa guerra de/ ninguém/ Dois braços sei tu levavas/ com quantos voltas não sei..." (HORTA, 1983 , p. 250). Sobre a relação entre a dor privada e o discurso público em contexto de guerra, ver p.ex. Acton, 2007.

2 Vem a propósito recordar que a prestação de serviço militar era obrigatória, o que torna tanto mais abstrusa a observação do historiador Rui Ramos de que "talvez" pelo que considera ter sido proporcionalmente um número reduzido de baixas, "o recrutamento nunca foi um problema" (RAMOS et al., 2009, p. 684).

3 O conceito de "pós-memória" foi desenvolvido em meados dos anos 90, no contexto da reflexão sobre o Holocausto, por Marianne Hirsch, que o define do seguinte modo: “'Pós-memória’ aponta para a relação da segunda geração com experiências marcantes, muitas vezes traumáticas, que são anteriores ao seu nascimento, mas que, não obstante, lhes foram transmitidas de modo tão profundo que parecem constituir memórias em si mesmas." (HIRSCH, 2008, p. 103).

4 No extremo oposto, cabe perguntar: e como lidaram os "filhos de Hitler" com a pesada herança de serem filhos de nazis, na sociedade pós-Segunda Guerra Mundial? Esse foi o trabalho realizado pelo jornalista Gerard L. Posner (1996), publicado sob o título, Os Filhos de Hitler - filhos de dirigentes do Terceiro Reich falam dos seus pais e de si próprios e o resultado é muito interessante, começando logo pela dificuldade sentida pelo jornalista em identificar os filhos. Na literatura de expressão alemã, este é um tema relevante sobretudo a partir do final dos anos 60, como é visível em alguns textos autobiográficos de filhos de dignitários nazis, por exemplo, o "romance-ensaio" de Bernward Vesper, A viagem. As referências extremas do Holocausto e do Nazismo podem ajudar-nos a pensar o que significará ser-se portador de uma identidade nunca escolhida, mas que inevitavelmente se cola à pele, pois, no fundo, tudo começa pelo nome, com que cada descendente carrega uma herança que lhe foi transmitida, seja pelas vítimas, seja pelos perpretadores.

5 Este projeto, financiado pela Fundação para a Ciência e Tecnologia e desenvolvido no Centro de Estudos Sociais da Universidade de Coimbra entre 2007 e 2011, incluiu tanto a recolha de testemunhos da segunda geração como a apreciação crítica da produção artística e cultural da pós-memória (fenómeno não só em curso mas em clara fase de expansão). Foram membros da equipa do projeto: Margarida Calafate Ribeiro (CES-UC, investigadora responsável), António Sousa Ribeiro (FLUC/ CES-UC), Luísa Sales (Hospital Militar de Coimbra/CES-UC), Roberto Vecchi (Universidade de Bolonha/CES-UC), Rui Mota Cardoso (Faculdade de Medicina da Universidade do Porto/CES-UC). Investigadores Juniores: Aida Dias (CES-UC), Hélia Santos (CES-UC), Ivone Castro Vale (Faculdade de Medicina da Universidade do Porto), Luciana Silva (CES-UC), Mónica Silva (CES-UC).

6 "Para os meus pais, que viveram este livro para além das palavras", dedicatória de Rodrigo Guedes de Carvalho, Daqui a Nada; "Para os meus pais", dedicatória de José Rodrigues dos Santos, O Anjo Branco; "Este é o espaço para a impressão digital dos meus pais", dedicatória de Norberto do Vale Cardoso, Impressão Digital. 